\title{
Pseudopapilloedema in the linear naevus syndrome
}

\author{
S H Campbell, A Patterson
}

Abstract

This case report describes the ophthalmic findings in a child with the linear naevus syndrome. The patient was referred by the Department of Paediatric Neurology with 'unilateral papilloedema'. This was thought to be a form of pseudopapilloedema, a finding that has not been previously described in this syndrome.

The linear naevus syndrome is a rare condition first described by Jadassohn in $1895 .^{1}$ Other names include the epidermal naevus syndrome, the sebaceous naevus syndrome, ${ }^{2}$ the naevus of Jadassohn, Feuerstein-Mimms syndrome, ${ }^{3}$ oculo-neuro-cutaneous syndrome of Schimmelpenning, ${ }^{4}$ organoid naevus phacomatosis, ${ }^{5}$ Solomans's syndrome, ${ }^{6}$ and several combinations of the above..$^{7-9}$

\section{Case report}

A male child born in 1982 following a normal pregnancy was noted at birth to have a cyst in his mouth and a blister on the lip. Several weeks after birth a patch of pigmented, hyperkeratotic skin developed below the chin on the left side extending from behind the ear down onto the neck. The blister on the lip became more obvious and was noted to blanch. At the age of 13 months he started having seizures and there was developmental delay.

Royal Liverpool Children's Hospital, Alder Hey, Eaton Road, Liverpool L12 2AP S H Campbell A Patterson

Correspondence to: S H Campbell.

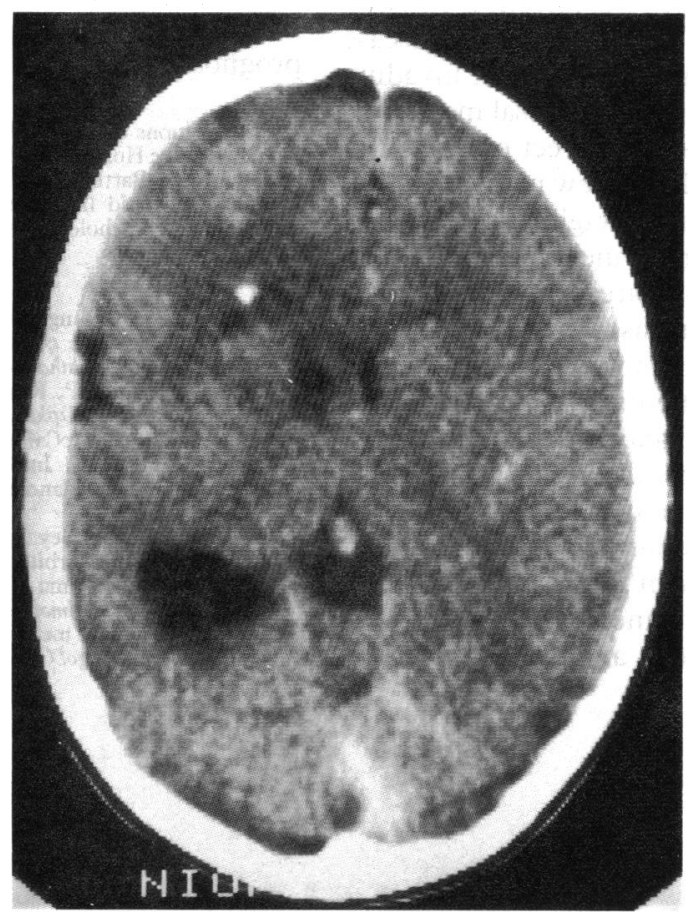

Figure 1 CT scan demonstrating low density lesion in the left frontal lobe with nodule of calcification.
A dermatological opinion was sought on the nature of the skin lesion. Several areas of epidermal, sebaceous naevi on the face, lips, and left side of the neck were noted.

An ophthalmic opinion noted an intermittent, divergent squint with equal fixation with each eye and normal fundi. A paediatric dental opinion reported hypoplasia/hypocalcification of teeth.

A computed tomographic (CT) scan demonstrated an extensive low density lesion in the left frontal lobe containing one small nodule of calcification. There was no displacement of mid-line structures.

An EEG showed abnormalities of both hemispheres, particularly the left, with multifocal discharges and excess of irregular slowwave activity.

A left internal carotid angiogram was performed and showed no evidence of pathological circulation or other abnormality. By 1985 a mild right hemiparesis with hemianopic inattention on the affected side and mental retardation were apparent. A repeat CT scan showed no change. In 1990 left unilateral papilloedema was noted. A CT scan showed little change (Fig 1) although there was some midline shift. The CT appearances were consistent with the mild right hemiparesis and hemianopic attention defect. Magnetic resonance image (MRI) scanning was not considered likely to yield further useful information.

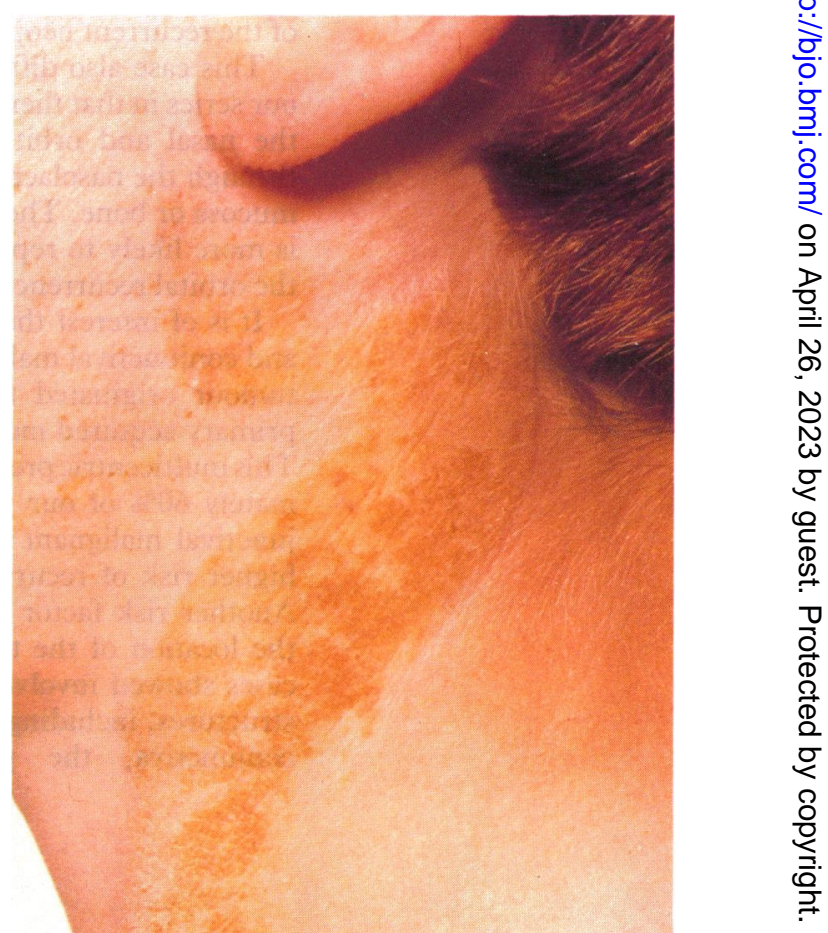
neck. 


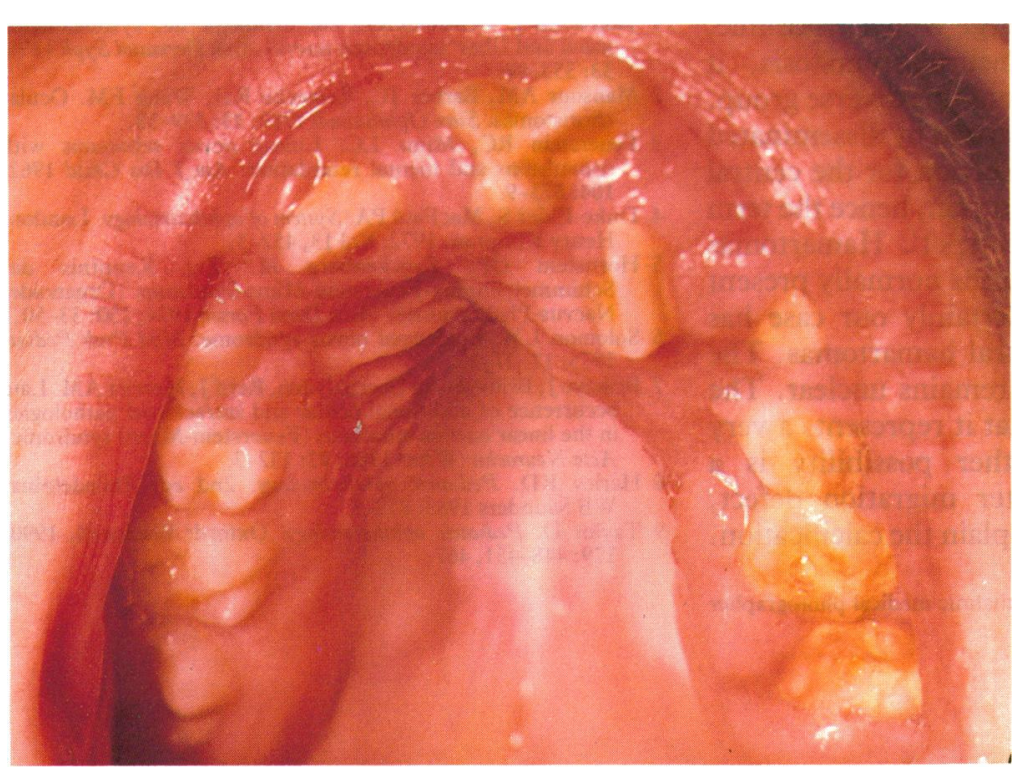

Figure 3 Abnormal dentition and enlarged lips on the left.

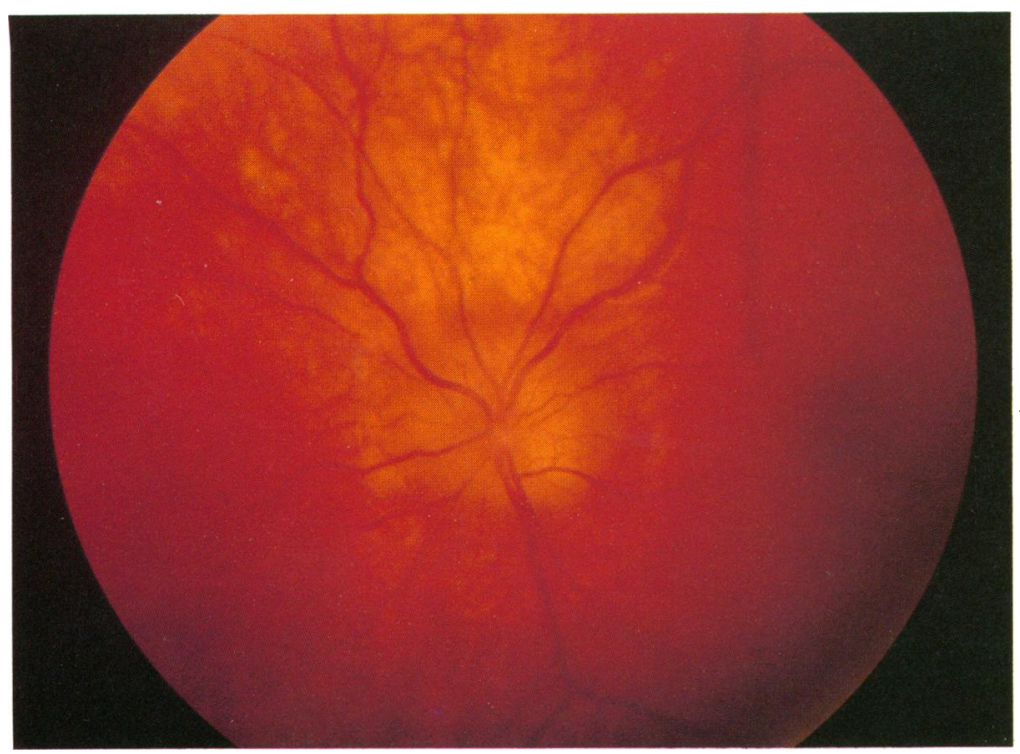

Figure 4 Left optic disc swelling.

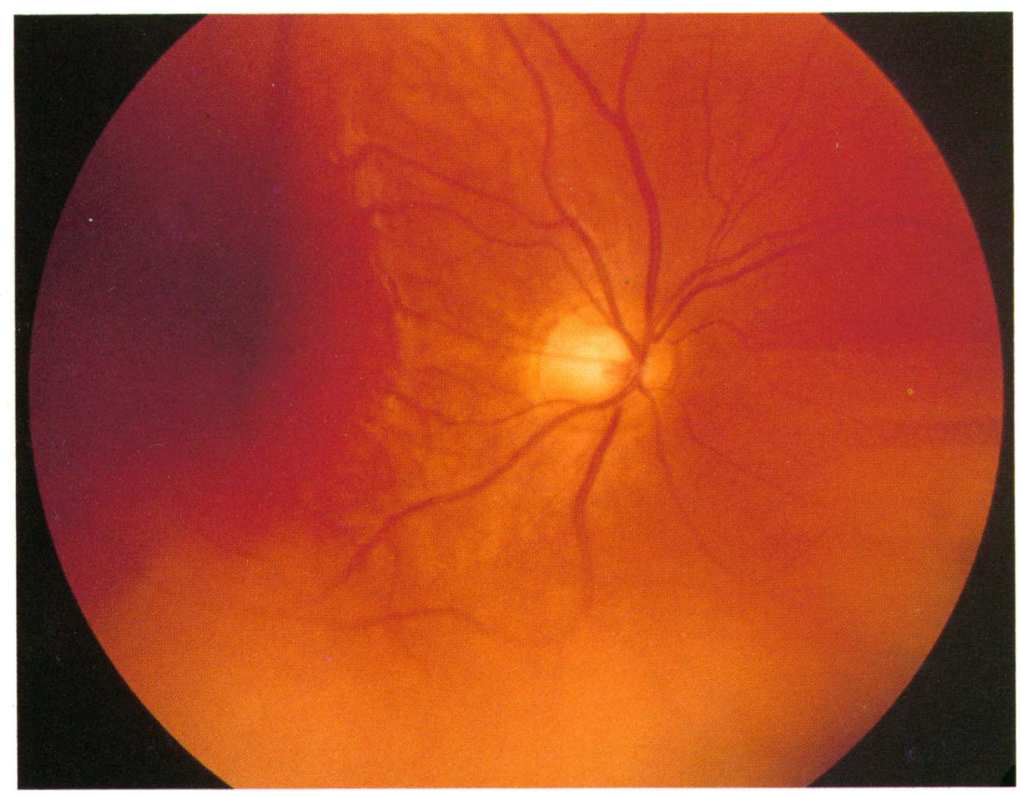

Figure 5 Temporal pallor of right optic disc.
The most recent CT scan (August 1991) showed no change in the calcification or the low density area occupying most of the frontal lobe. There was no alteration in the position or size of the ventricles and no abnormality of the optic nerves. The child was referred for an ophthalmic opinion.

Ocular history was of an intermittent squint, the left eye turning out since birth, especially when tired. Examination revealed the linear sebaceous naevus on the left side of the neck (Fig 2 ), and the abnormal dentition (Fig 3). Visual acuities were $6 / 6$ left and right. Orthoptic examination demonstrated a simulated distance exotropia, measuring 14 prism dioptres base in at one third of a metre and $45+$ dioptres base in at 6 metres and $15^{\circ}$ on the synoptophore. Gross binocular function was preserved. There was some right hemianopic inattention. Ocular movements and pupil responses were normal and there were no cranial nerve defects. Cycloplegic refraction was $+0.5 \mathrm{DS}$ right and left. Fundi showed left optic disc swelling (Fig 4) and temporal pallor of the right optic disc (Fig 5).

\section{Discussion}

The linear naevus syndrome, although rare, is of interest to several of the clinical specialities including ophthalmology. Mansour et $a l^{2}$ describe the syndrome as manifesting skeletal, neurological, vascular, and dermatological disorders. The skin lesions are congenital, epidermal, linear, and rarely cross the midline. They tend to occur on the head and face and are of two types. Linear epidermal naevi are characterised by brown linear unilateral papules with hyperpigmentation and hyperkeratosis. When the lesions have many sebaceous glands they are called sebaceous naevi. These have been known to undergo malignant change early in life, and are also associated with systemic malignancies. Ocular findings are detailed by Mansour et $a l^{2}$ and Taylor and include ptosis, conjunctival dermoids, colobomas, and Coats' disease.

Taylor lists the aetiology of unilateral optic disc swelling in childhood under six headings: pseudopapilloedema, tumours (involving the optic nerve head), uveitis, ischaemic optic neuropathy, papillitis, and papilloedema which may be asymmetrical. The most likely explanation in this case is pseudopapilloedema. Buried drusen are the commonest cause and have been described in numerous and diverse ocular and neurological disorders including tuberous sclerosis. Glial anomalies of the optic disc head are another possibility. Optic nerve head drusen may be detected by their autofluorescence, and on fluorescein angiography, when they hyperfluoresce but do not leak dye. CT scanning will demonstrate large calcified drusen. Unfortunately in this case angiography was not possible due to the patient's age and developmental delay. A recent CT scan of the optic nerves did not demonstrate the presence of disc drusen.

Some authors have called the syndrome the fifth phacomatosis. ${ }^{7}$ However with the inclusion of Wyburn-Mason syndrome along with Von 
Hippel Lindau disease, Sturge Weber syndrome, tuberous sclerosis and neurofibromatosis, it becomes the sixth member of this diverse group. The conditions are characterised by disseminated hamartomas, with a predilection for the central nervous system, retina, and skin, hence the term 'phakomatosis' or 'mother spot'. Hamartomas are tumours composed of cells normally present in the involved tissue. Certainly our case has cutaneous and probably oral hamartomas. The nature of the CNS lesion remains unclear. The most likely diagnosis is that it represents a very low grade glioma. Another possibility is a localised grey/white matter migration defect, although this would not explain the calcification.

The authors thank Paul Bloor, ophthalmic medical photographer for providing the photographs.
1 Jadassohn J. Bemerkungen zur histologie der systematisiten naevi und Über 'talgdrusen-naevi'. Arch Dermatol Syph 1895; 33: 355-94

2 Mansour AM, Barber JC, Reinecke RD, Wang FM. Ocular choristomas. Surv Ophthalmol 1989; 33: 339-58.

3 Feuerstein RC, Mims LC. Linear nevus sebaceous with convulsions and mental retardation. Am $\mathcal{F}$ Dis Child 1962; 104: 675-9.

4 Duke-Elder S, MacFaul PA. System of ophthalmology. London: Henry Kimpton, 1972: Vol 13, 452-3.

5 Hornstein OP, Knickenberg M. Zur Kenntnis des Schimmelpenning-Feuerstein-Mims-Syndroms (Organoide-

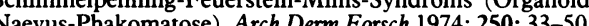
6 Solomon LM. Epidermal nevus syndrome. Mod Prob Pediatr 1975; 17: 27-30.

7 Brihaye J, Brihaye-van Geertruyden, Retif J, Mercier AM. Late occurrence of additional ocular and intracranial pathologies in the linear naevus sebaceous (Feuerstein-Mims) syndrome. Acta Neurochir (Wein) 1988; 92: 132-7.

8 Harley RD. Pediatric ophthalmology. 2nd ed. Philadelphia: WB Saunders 1983: 852-3.

9 Taylor D. Pediatric ophthalmology. Oxford: Blackwell, 1990: 179: 448-451, 467 . 